\title{
SURGICAL-ORTHODONTIC TREATMENT OF IMPACTED PERMANENT CANINES IN THE MANDIBLE: TWO CASE REPORTS
}

\author{
Agnieszka Topka, Bogna Racka-Pilszak, Anna Wojtaszek-Słomińska, Maria A. Orzelska-Blomberg \\ Department of Orthodontics, Medical University of Gdansk, Gdansk, Poland
}

\begin{abstract}
Dental eruption disorders occur frequently, affecting almost $20 \%$ of the population. They include canine impaction, with an incidence of $0.9-4.3 \%$ of patients. The aim of the study was to present the authors' experience in bringing impacted mandibular canines to the occlusal plane using fixed appliances. Two case reports of patients who presented for treatment at the Orthodontic Clinic of Medical University of Gdansk have been described.

Two 11-years-old patients were orthodontically diagnosed. In both cases, impacted canines were revealed. Treatment plan included orthodontics and surgical treatment of tooth 43 , so that it could be aligned into the arch. The treatment was performed with fixed straight wire appliance. The effect of treatment in both cases was good, with toot 43 its right positions. Treatment time lasted 3 and 2.5 year, respectively.

Impacted mandibular canines are of rare occurrence, of which management poses therapeutic difficulties. Both aesthetics and occlusion determine the proper choice of treatment, so that the canine is brought back to the arch by using surgical and orthodontic extrusion. In order to minimize the risk of complications, early diagnosis is necessary as well as close interdisciplinary cooperation of an orthodontist and surgeon.
\end{abstract}

KEY WORDS: impacted tooth, lower canines, ortho-surgical treatment.

J Stoma 2019; 72, 6: 282-290

DOI: https://doi.org/10.5114/jos.2019.93848

\section{INTRODUCTION}

Dental eruption disorders occur frequently, affecting almost $20 \%$ of the population. They include tooth impaction, with an incidence of $0.9-4.3 \%$ of patients [1]. An impacted tooth possesses a fully formed root, but has not erupted in its proper physiological time, retaining in bone. If we disregard third molars, canines constitute the majority of impacted teeth accounting for 0.9 to $2.2 \%$ in the maxilla, and 0.05 to $0.4 \%$ in the mandible $[2,3]$.

In the available literature, one can find many papers on ectopic maxillary canines, but when it comes to the mandibular reports, the number of publications is limited, since this abnormality is relatively less frequent in the lower jaw. Aydin et al. [4] reviewed 4,500 OPGs patients from Turkey, and managed to identify twenty cases of canine impaction in the mandible (0.44\%). Grover and Lortan [5] confirmed only eleven cases of this anomaly in 5,000 examined patients $(0.22 \%)$. Another study describes five cases of impacted mandibular canines in 7,486 patients $(0.07 \%)$ [6].

There are few reports published concerning the incidence of canine impaction in relation to gender. Aydin and Ericson observed that this disorder more frequently affects women, with male to female ratio of $1: 1.22$ [4], whereas Ericson reported a twofold incidence in women [7].

\section{JOURNAL OF} STOMATOLOGY CZASOPISMO STOMATOLOGICZNE

AdDRESS FOR CORRESPONDENCE: Dr. Maria A. Orzelska-Blomberg, Department of Orthodontics, Medical University of Gdansk, Gdansk, Poland, e-mail: orzelska@gumed.edu.pl

RECEIVED: 24.01.2020 • ACCEPTED: 11.02.2020 • PUBlished: 09.03.2020 
Most of the impacted canines in the mandible occur unilaterally and are located labially to the alveolar process [4]. Nodine [8] also reported that the left canine in the mandible is affected more frequently than the right one.

Selim Yavuz et al. [9] introduced two classifications of impacted canines in the mandible based on angulation and depth of impaction in the bone. As for the first criterion, the author categorized mandibular ectopic canines as mesioangular, distoangular, vertical, and horizontal. Considering the depth of impaction, the authors distinguished: level A (the cusp of impacted canine lies at the height of the cervical line of adjacent teeth), level B (the cusp of impacted canine lies between the cervical line and apices of adjacent teeth), and level C (the cusp of impacted canine lies beneath the apices of adjacent teeth). Mlosek [10] introduced a similar classification (based on the depth of bone impaction). He proposed superficial position (corresponding to level A), indirect position (level B), and deep position (identical to level C, according to Selim Yavuz).

Madnuson and Kjellberg [11] differentiated two groups of causes of tooth impaction: systemic ones, which concern multiple impactions, and local factors, usually affecting a single tooth. Systemic causes include genetic syndromes (Gorlin-Gotz syndrome, cleidocranial dysostosis, Apert syndrome, or endocrine disorders). Local factors include: mechanical barriers (accessory teeth, cysts, and tumors), crowding of teeth, premature exfoliation of deciduous teeth, craniofacial skeleton abnormalities, developmental malformations, or improper position of tooth germs, or pathologies of or damage to periodontal structures.

Most of the fully impacted canines are clinically asymptomatic. A number of authors, however, list symptoms such as transmigrations and arch length discrepancy, dysesthesia, neuralgia, and alveolar fistula, resulting from chronic inflammation of dentigerous cyst [12].

There are several modalities concerning the management of ectopic teeth such as surgical removal, leaving them in the bone, autotransplantation, and combined surgical and orthodontic procedure to align them to the arch [13]. Surgical procedure involves flap reflection and bonding an attachment to the impacted tooth. After the periosteal flap is repositioned, the ligature is brought to the oral cavity. The orthodontic part of the treatment aims at both, regaining sufficient space in the dental arch for the tooth, which is being repositioned and creating proper occlusion. Bringing impacted teeth to the line of occlusion can be done by using removable appliances, archwires, and mini-implants [14].

The aim of the study was to present the authors' experience in bringing impacted mandibular canines to the occlusal plane by using fixed appliances. Two case reports of patients who presented for treatment at the Orthodontic Clinic of Medical University of Gdansk have been described.

\section{CASE PRESENTATION}

\section{CASE 1}

An 11-year-old female patient presented at the Orthodontic Clinic of Medical University of Gdansk for orthodontic check-up. Extra-oral examination of the patient revealed transfrontal profile according to Izard, straight profile as per Schwarz, and unaffected facial symmetry. Intra-oral examination revealed: mixed dentition, partial bilateral crossbite, shallow overbite, Angle's class I on both sides of the arch, and lack of space for tooth 13 (Figure 1). In the lower arch, a partially erupted tooth 33 was visible, while tooth 83 showed no signs of physiological mobility.

A panoramic radiograph revealed tooth 43 , with a widened dental follicle and mesioangular inclination (at an angle of approximately $45^{\circ}$ ), which cusp was at the height of apex of tooth 42 . All the germs of permanent teeth were present (Figure 2). The analysis of lateral cephalogram revealed skeletal class I according to ANB $\left(-1^{\circ}\right)$, WITS class III $(-5.6 \mathrm{~mm})$, weak anterorotation of mandible $\left(\mathrm{GoGn}\right.$ to $\mathrm{SN}=35^{\circ}$ ), inclination of upper incisors (UI to $\mathrm{N}-\mathrm{A}=4.5 \mathrm{~mm}$ ), and tipping of lower incisors ( $\mathrm{LI}$ to $\mathrm{N}-\mathrm{B}=1.3 \mathrm{~mm}$ ).

Treatment plan included expansion of the upper arch, regaining space for tooth 13 , and surgical orthodontic treatment of tooth 43 , so that it could be aligned into the arch.

The treatment commenced with the application of the upper fixed Roth appliance, with a 0.018 inch slot. Its active phase in the upper arch was started with $0.016 \mathrm{NiTi}$ archwire, which was subsequently replaced with $0.016 \times 0.022$ $\mathrm{NiTi}, 0.016 \times 0.022 \mathrm{SS}$, and $0.017 \times 0.025 \mathrm{SS}$. The space for tooth 13 was regained by using expansion springs.

After about six months, the persistent milk tooth 83 was removed and a fixed appliance was placed in the lower arch (Roth 0.018). The active phase of treatment in the lower arch was performed by using 0.014 $\mathrm{NiTi}, 0.016 \mathrm{NiTi}, 0.016 \times 0.022 \mathrm{NiTi}, 0.017 \times 0.025 \mathrm{NiTi}$, and $0.016 \times 0.022 \mathrm{SS}$ arches. After one year, it was evident that tooth 43 failed to erupt spontaneously, therefore, a control OPG was taken to assess its position. Its analysis revealed that the position of the impacted tooth deteriorated and it was placed horizontally at the height of apices of teeth 41 and 42 (Figure 3). The patient was referred to the Oral Surgery Clinic, Medical University of Gdansk, to expose tooth 43 , bond a bracket, and bring out the metal ligature. Post-operatively, the elastic module was replaced every three weeks, so that tooth 43 could be extruded to the arch. Then, an additional 0.016 steel arch with a bent loop was placed atop the base arch, and the ligature pulling the impacted tooth was tied to the loop. The lever was activated every three weeks. After six months, a control radiograph was taken, which revealed significant improvement in the vertical dimension of tooth 43 (Figure 4). At one year post-operative- 

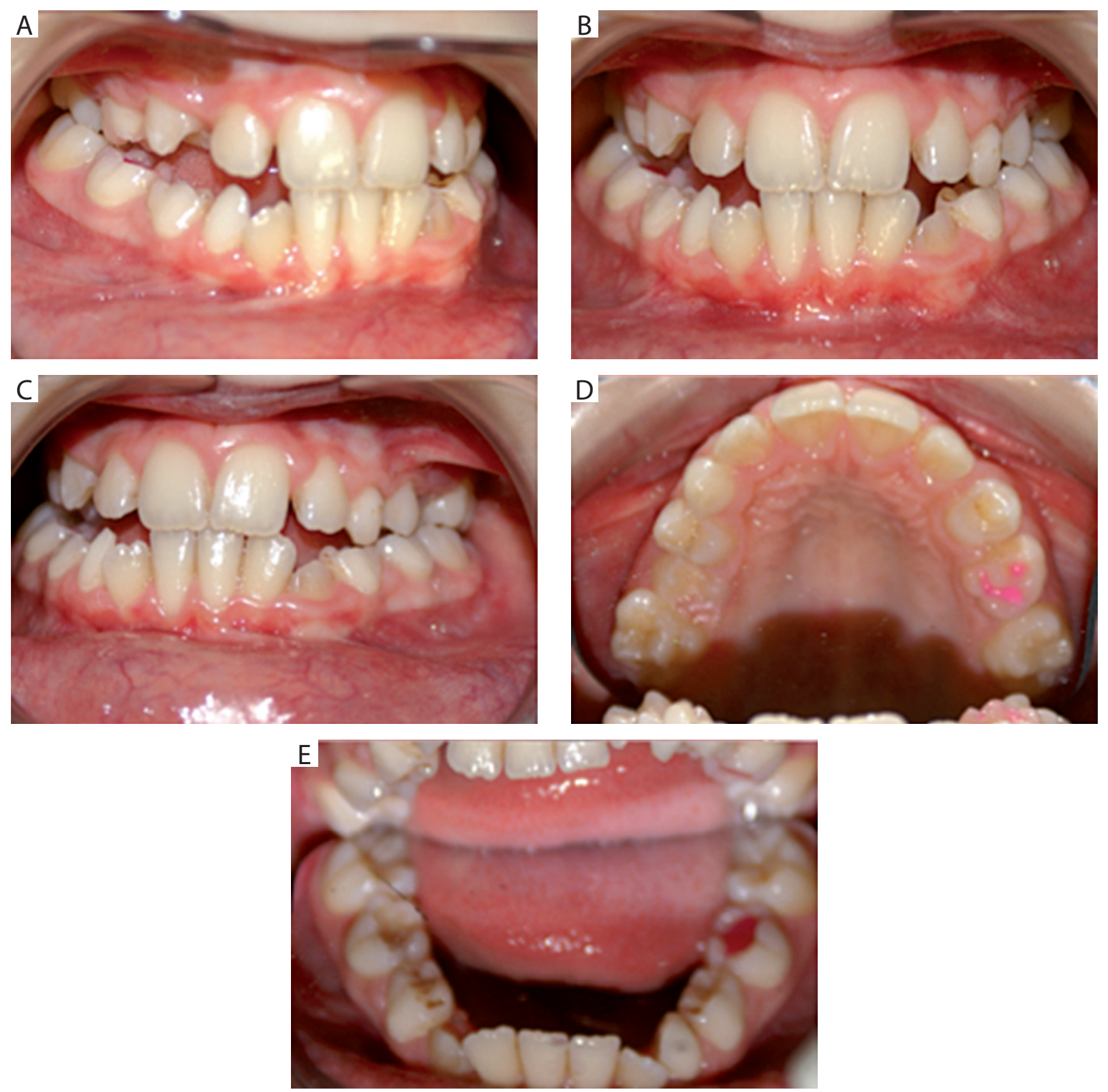

FIGURE 1. Case 1. Intraoral photographs. Before treatment

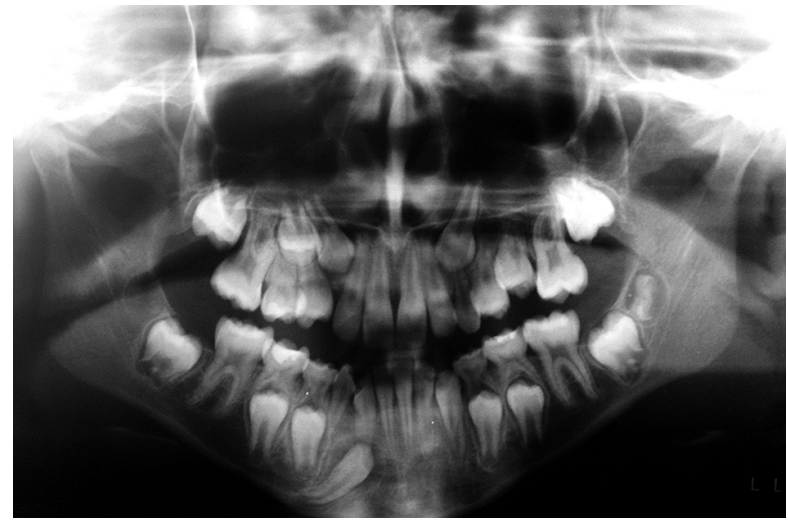

FIGURE 2. Case 1. Begining panoramic X-ray

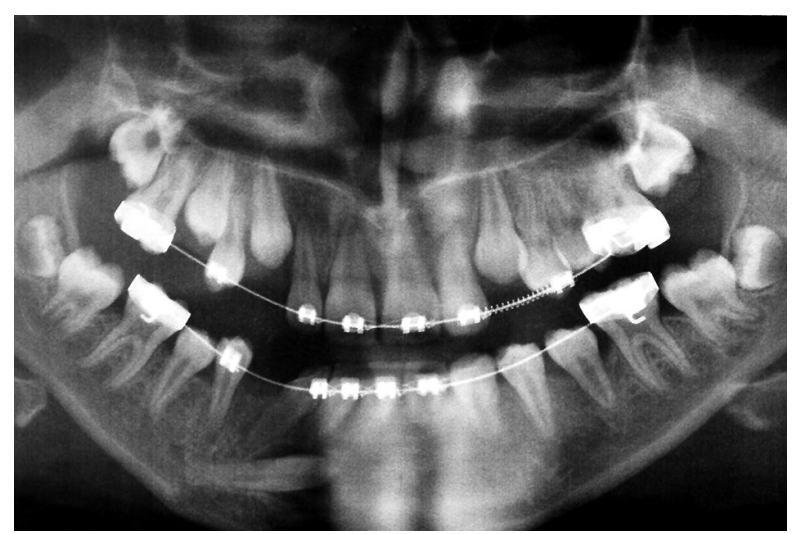

FIGURE 3. Case 1. Control panrepo X-ray 


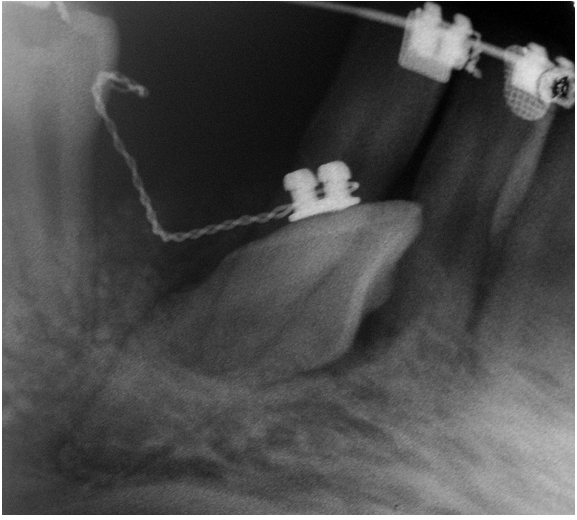

FIGURE 4. Case 1. Control X-ray of tooth 43
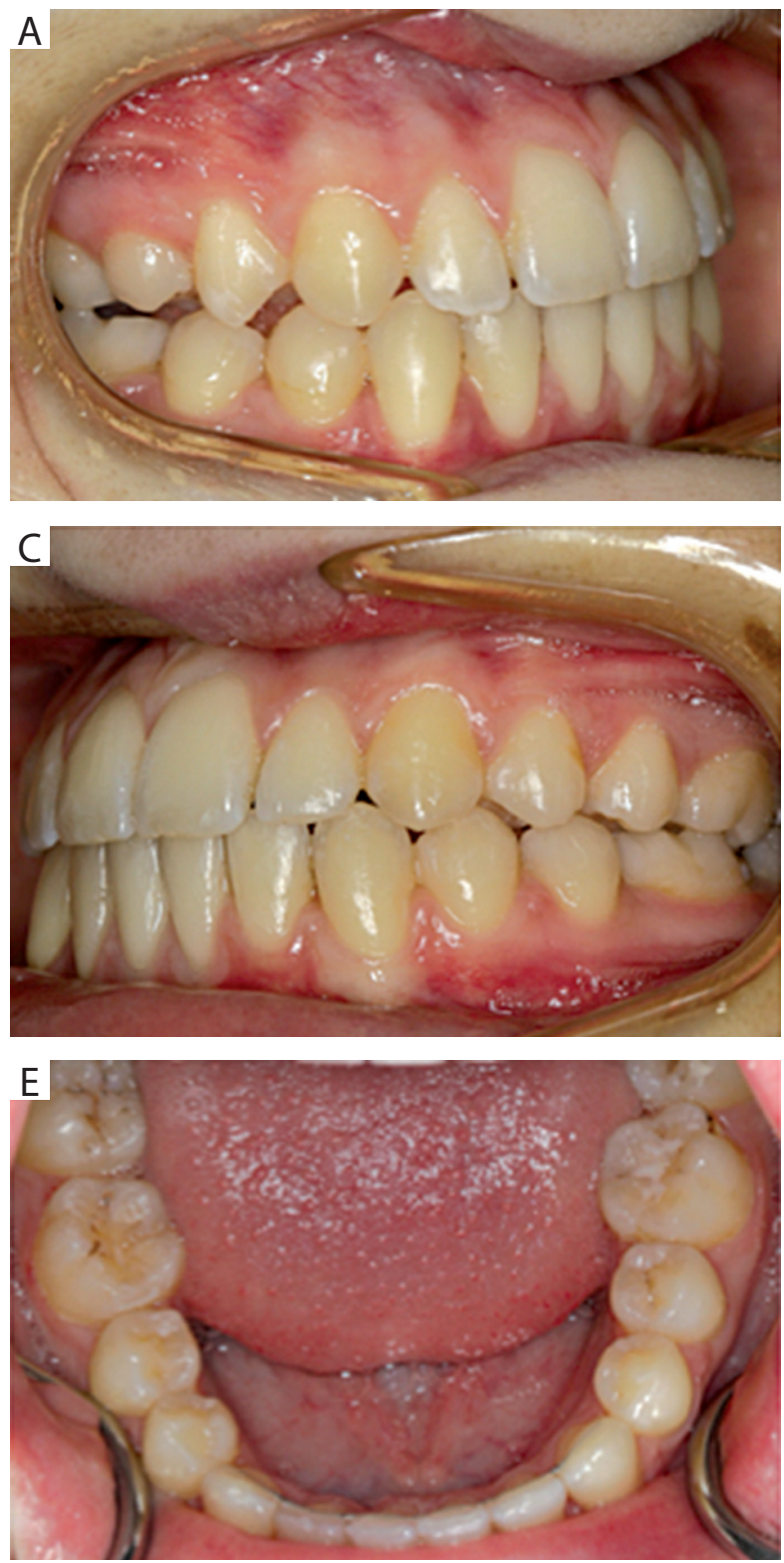

ly, the crown of tooth 43 became palpable in the oral vestibule. Gingival hypertrophy was also noted in that area. The patient was referred for gingivectomy. Then,

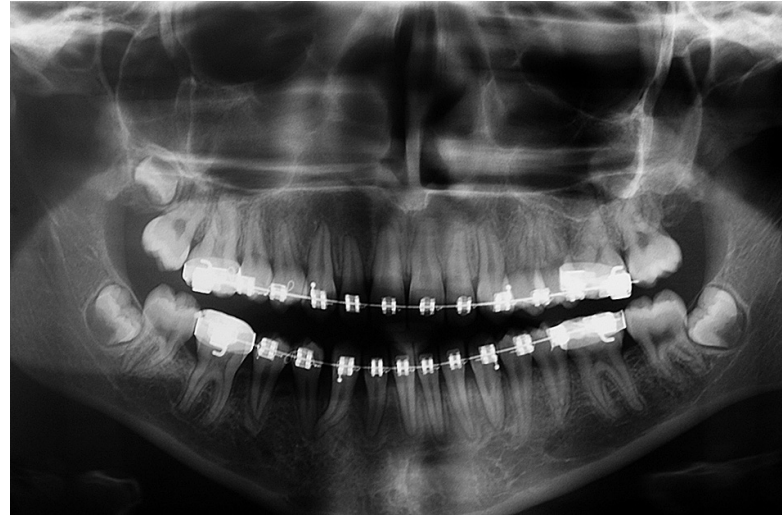

FIGURE 5. Case 1. Panoramic X-ray before debonding
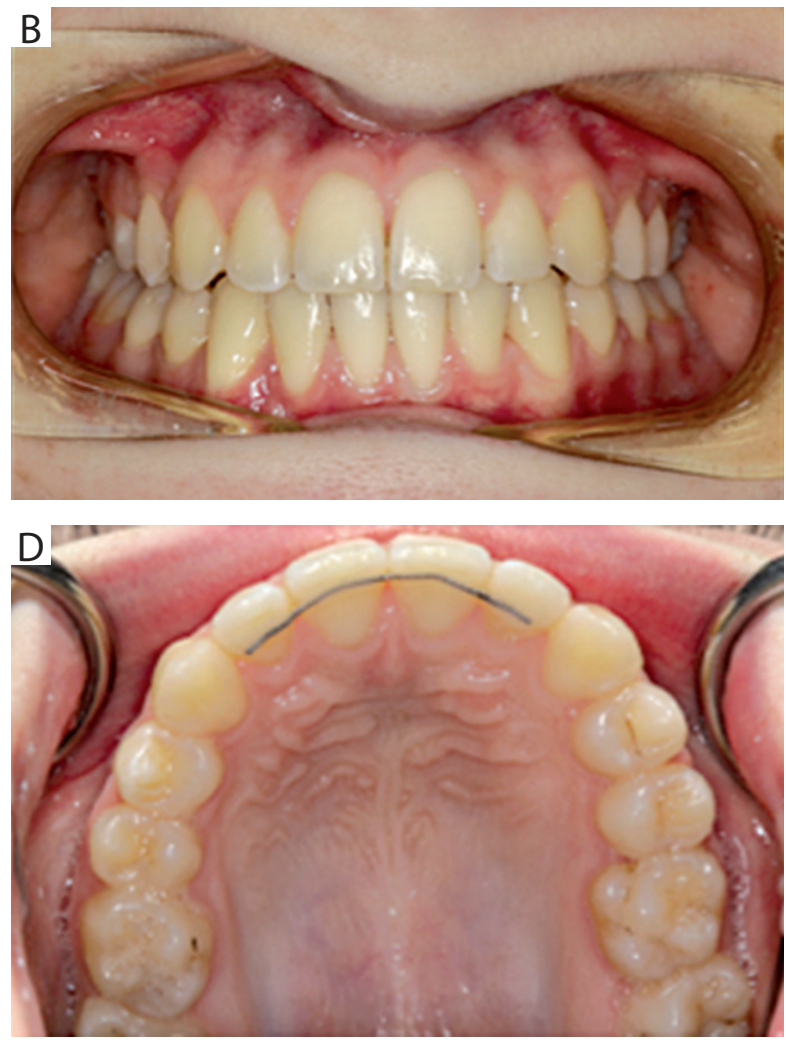

FIGURE 6. Case 1. Intraoral situation after debonding (final occlusion)

the lower archwire was replaced with $0.017 \times 0.025$ SS, and the elastic module was replaced every three weeks to extrude tooth 43. After premolars had erupted, additional brackets were bonded and the treatment continued in both arches. One month before the planned removal of the appliances, an OPG picture was taken, which conformed proper position of roots (Figure 5). The extruded tooth had distal dilaceration, and slight root resorption was observed at teeth 41 and 42 . Total duration of treatment was three years, due to unfavorable position of the impacted tooth and complications caused by its extrusion (Figure 6). 
Retention involved preparation of a retentive plate in the upper arch and bonding permanent retainers at the upper incisors as well as the lower incisors and the canines. Four months after finishing the therapy, the stability of outcome was assessed as very good, and no change in the position of tooth 43 was observed.

\section{CASE 2}

An 11-year-old male patient presented at the Orthodontic Clinic, Medical University of Gdansk for continuation of treatment that had been started at a different facility. The patient used removable appliances on both arches. Extra-oral examination of the patient revealed: transfrontal profile according to Izard, straight as per Schwarz, and retained facial profile. On intra-oral exa- mination: Angle's class II (half of a cusp) on both sides of the arches, tipping of upper incisors, and deepened overbite (Figure 7). A partially erupted tooth 33 was visible in the mandible; in the fourth quadrant, tooth 83 displayed no physiological mobility. An OPG showed an impacted tooth 43 positioned mesioangularly (at an angle of approximately $30^{\circ}$ ), which crown corresponded to the position of the apex of tooth 42 . All the germs of permanent teeth were present (Figure 8). For a more accurate assessment of the vicinity of impacted tooth, an additional X-ray picture was taken, which revealed a supernumerary tooth (Figure 9). The patient's caregivers consented to the continuation of treatment with the previously utilized removable appliance. Tooth 83 was removed. Half a year later, tooth 43 failed to erupt spontaneously, and a decision was made to introduce
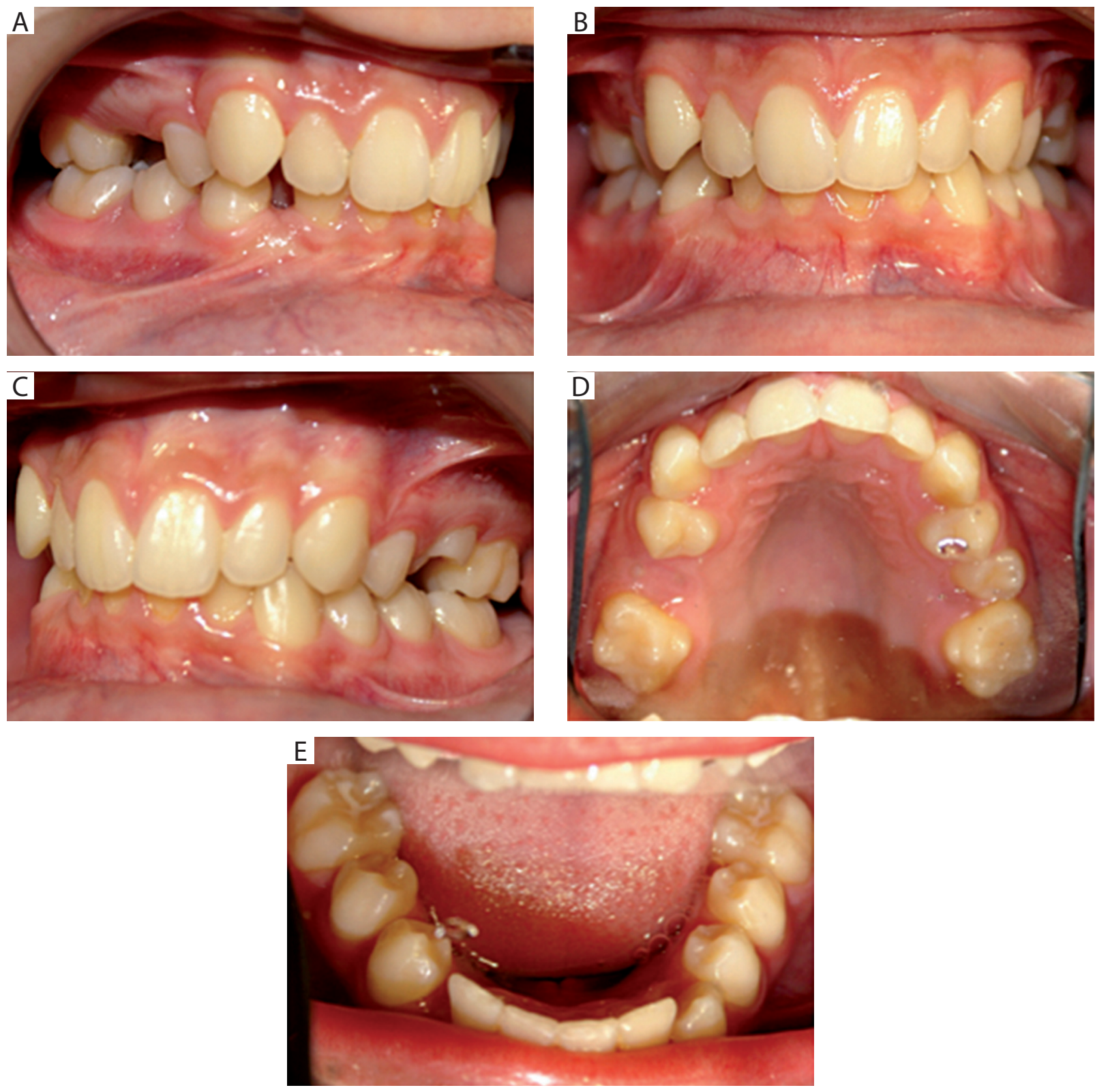

FIGURE 7. Case 2. Intraoral photographs. Before treatment 


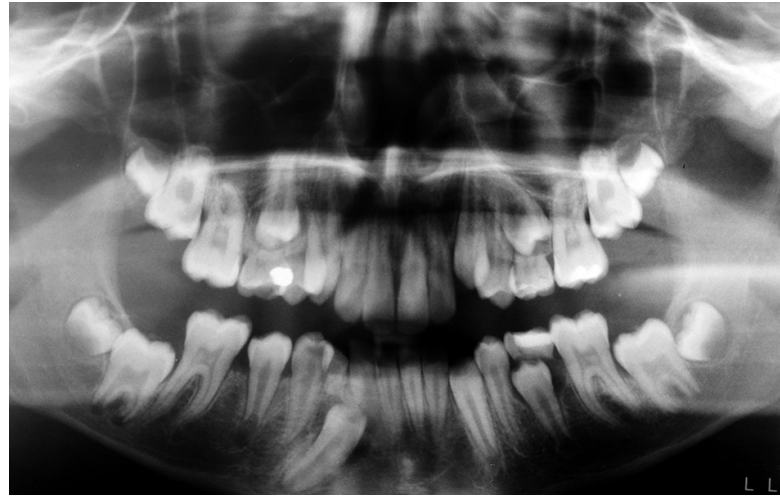

FIGURE 8. Case 2. Begining panoramic X-ray

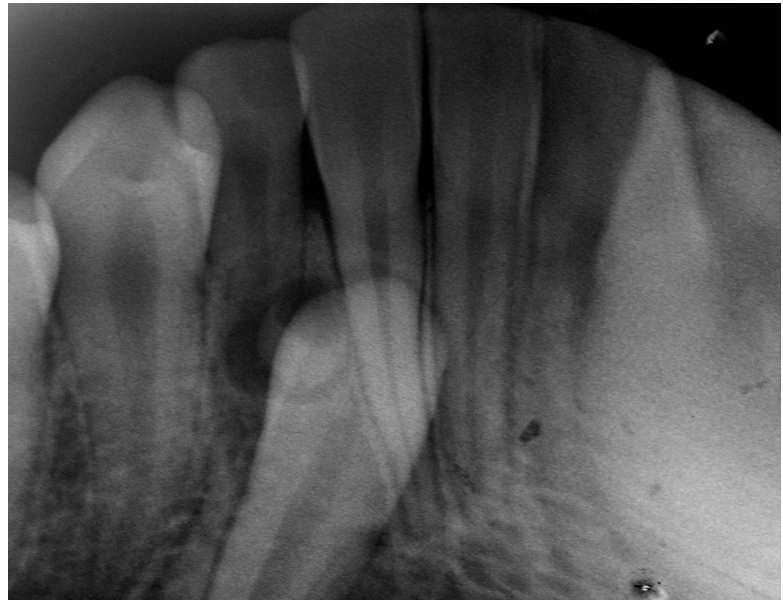

FIGURE 9. Case 2. Control X-ray of day 43. Supernumerary tooth present

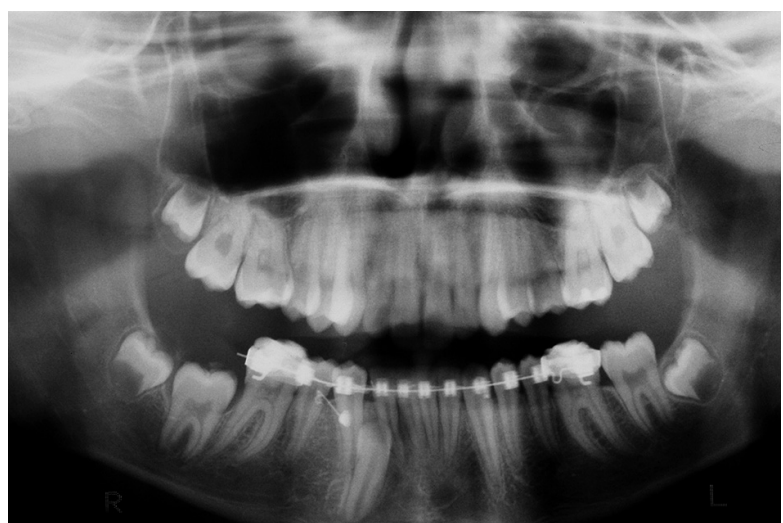

FIGURE 10. Case 2. Control panoramic X-ray. Debonded bracket on tooth 43

a fixed appliance (Roth, 0.018 inches) in the lower arch. The treatment started with a $0.016 \mathrm{NiTi}$ archwire, with a spring to regain space for tooth 43 . The patient was referred to the Oral Surgery Clinic, Medical University of Gdansk, for the removal of the supernumerary and exposure of tooth 43 to bond a bracket and bring out a metal ligature. The active phase of treatment was carried out with $0.016 \mathrm{NiTi}, 0.016 \times 0.022 \mathrm{NiTi}, 0.017 \times$

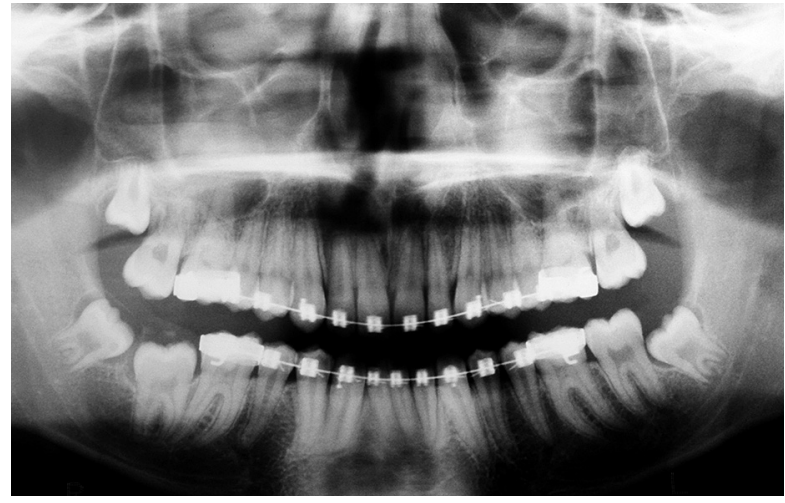

FIGURE 11. Case 2. Panoramic X-ray before debonding

$0.025 \mathrm{NiTi}$, and $0.017 \times 0.025 \mathrm{TMA}$ archwires; the elastic module was replaced every three weeks to extrude tooth 43. At six months post-operatively, following a suspicion that the bracket de-bonded, another OPG was taken, which revealed straightening of the tooth and the de-bonded bracket (Figure 10). At the same time, since there was practically no space for the tooth 43 undergoing extrusion, it was decided to extract tooth 42 as expansion springs failed to regain space. In the Oral Surgery Clinic, two procedures of the tooth 42 extraction and bracket re-bonding for tooth 43 were performed. Then, an additional 0.016 stainless steel archwire with a bent loop was placed atop the base arch. The ligature pulling the impacted tooth was tied to the loop. At three months post-operatively, tooth 43 became visible in the mouth and after four months, the ultimate bracket was attached and included in the basic archwire. The total time of canine extrusion was ten months. In order to improve the aesthetics and the upper and lower arch occlusal relationship, it was decided to undertake treatment with braces in the upper arch. After two years of treatment, a control OPG was taken (Figure 11) to assess root positions. Its analysis revealed the need to rebond brackets on teeth 31 and 41 , but the root of the extruded tooth 43 was assessed as correct. An overall time of treatment was 2.5 years (Figure 12).

The retention phase involved the preparation of a retentive plate in the upper arch and bonding permanent retainers lingually to maxillary incisors as well as to incisors and canines in the mandible. Twelve months after finishing the therapy, the stability of outcome was assessed as very good, and no change in the position of tooth 43 was observed. Due to the presence of gingival recession of tooth 43 , the patient was monitored by a periodontologist, who proposed coverage of the recession with an autogenic transplant at the right age of the patient.

\section{DISCUSSION}

In the human dentition, maxillary and mandibular canines play significant roles due to the shape and length of the root, which determine their longevity in the mouth. 

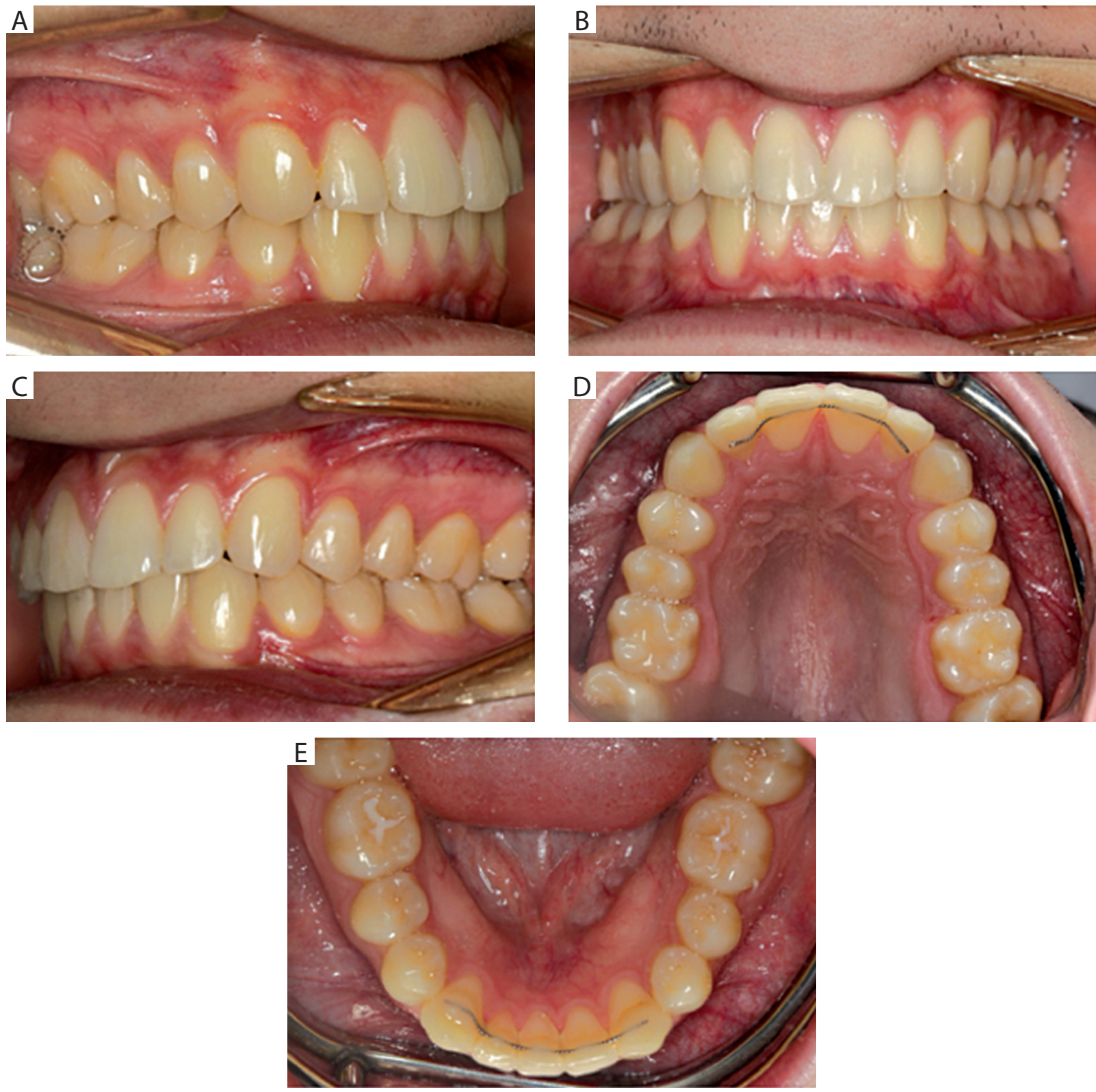

FIGURE 12. Case 2. Intraoral situation after debonding (final occlusion)

The proper position of canines is of utmost importance from both the aesthetic and functional perspective. For this reason, when the treatment of impacted canines is planned, one should opt for their extrusion, and their removal should be regarded as the last resort [15]. According to Loboda [16], the option of bringing the canine into occlusion can only be abandoned in the following cases: if the tooth is malformed, its position prevents extrusion, the space it occupies in the arch cannot be regained, or if a previous extrusion attempt had failed.

The success of canine extrusion depends largely on its angulation and the distance to the occlusal plane. The prognosis should include the patient's age: the younger the patient, the higher the chance for positive outcome of treatment; with age, the canine changes its angulation to a less favorable [17].
In patients presented above, the canines had a mesioangular inclination (at angles of $45^{\circ}$ and $30^{\circ}$, respectively) with their cusps at the level of apices of lateral incisors (level C according to Selim Yavuz, deep position according to Mlosek). Similarly, the positioned teeth require time-consuming and cautious orthodontic treatment. Orton et al. [18] have claimed that treatment of impacted canines, which is commenced after puberty may last longer and result in failure. In both cases presented here, the patients' age coincided with the growth spurt, which definitely determined favorable treatment outcome.

Extrusion of canines can be accomplished by using removable appliances archwires and mini-implants [14]. Surgical procedures, employed to expose impacted teeth include open and closed methods [19]. One of the previously utilized methods is the open method, so-called 
"fenestration", which involves radical removal of bone and soft tissues covering the crown of impacted tooth. A bracket is bonded to the exposed coronal part, which is then protected with a surgical dressing. This method offers an advantage of full inspection and easy attachment of the bracket. Disadvantages include major patient discomfort resulting from wound granulation as well as noticeable violation of aesthetics due to the lengthening of clinical crown of the extruded tooth (gingival recession), which is a consequence of insufficient width of the attached gingiva [19]. Closed technique should be a method of choice, in which a trapezium-shaped mucoperiosteal flap is reflected towards the vestibule that exposes the coronal part of the impacted tooth [20]. Having removed part of the dental follicle from the crown surface, a bracket with ligature is bonded, the flap is repositioned and sutured for wound closure. The ligature extends from under the flap in the mid-section of the alveolar ridge. Activation of orthodontic forces extrudes the tooth through the alveolar ridge, which imitates the physiological process of eruption, ensures adequate volume of attached gingiva labially, creates conditions for the proper shaping of periodontium, and last but not least, is aesthetically pleasing [20].

The two cases described in this paper were treated with a closed method of exposure of impacted canines.

Nowadays, orthodontic mini-implants are becoming more and more popular for the extrusion of impacted teeth. Their use prevents uncontrolled orthodontic traction and overloading of periodontium of adjacent teeth. They also shorten the treatment phase with fixed appliances [21]. Autotransplantation is another treatment option in cases of canine impaction. During the procedure, a socket is created, in which the impacted tooth will be placed. The procedure is relatively quick, but burdened with a high-risk of pulpal necrosis of the extruded tooth, root resorption, and its subsequent loss due to damage to the vasoneurotic bundle. The prognosis depends on the stage of tooth development. Better outcome is predicted in immature teeth with incomplete apical closure [22].

The impacted canine can also be left in the bone. Such an option should be chosen in the presence of systemic contraindications to surgery, or whenever the impacted tooth lies deep in the bone, is asymptomatic, and its removal could provoke damage to, or mobility of adjacent teeth, or necessitate the removal of massive amount of bone. Also the presence of aesthetically acceptable deciduous canine with a well-preserved root may argue for leaving the impacted canine in the bone. Regrettably, this option may lead to long-term complications such as ankylosis of the retained tooth, or root resorption of the adjacent teeth. For this reason, impacted teeth left in the bone should be periodically monitored with radiographic examinations [23].

Finally, the removal of the impacted tooth ends the list of modalities. Indications include unfavorable position, improper morphology of the impacted tooth, its ankylosis preventing either extrusion or autotransplantation, the presence of neuralgia, and tumors or large cysts in its vicinity. Removal of an impacted tooth results in a massive loss of bony structure, which may exclude orthodontic, prosthetic, or combined implantoprosthetic treatment, and ultimately lead to post-operative gingival recessions of adjacent teeth [24].

The discussed treatment options are the same for teeth impacted in the maxilla and the mandible. However, treatment planning should consider the differences in the corresponding bony structures. Bone in the mandible is denser than in the maxilla, especially in the anterior segment, where density is the highest of all jawbones. Therefore, the application of stronger forces to move impacted lower teeth is necessary, treatment will last longer than that of the upper teeth, and more anchorage is required $[25,26]$. Regaining space in the mandible is more challenging than in the maxilla, as evidenced by Case 2 , where regaining space for the impacted tooth 43 orthodontically failed, necessitating the extraction of tooth 42 .

Considering the difficulties regarding the treatment of impacted mandibular teeth, the number of their extractions is higher than that of maxillary teeth. In the studies by Selim Yavuz et al. [14], from the total of seventy-one impacted mandibular canines, forty-one were removed, twenty-two extruded with surgical and orthodontic procedures, one was transplanted, and the remaining six were left in place for observation.

The treatment of patients with impacted teeth is difficult, since it carries the risk of complications including gingival recessions, root resorption of the impacted/adjacent teeth, pulpal necrosis, bracket debonding and retreatment [24].

Significant gingival recessions (extending beyond the muco-gingival junction) following canine extrusion were observed in Case 2. Doniec-Zawidzka [27] demonstrated in her studies that this complication is influenced by the way the vestibular mucoperiosteal flap is formed. Nowadays, attention is focused on the highly conservative removal of soft tissues and bone surrounding the tooth and the cementoenamel junction area. Extensive exposure of the crown during surgery may provoke too little or low marginal attachment of the gum around the extruded tooth, resulting in clinical crown lengthening and insufficient aesthetics [27].

The second complication, namely root resorption, was evidenced in Case 1. It is a frequent phenomenon in the treatment of patients with impacted teeth. A 3-mm root resorption of the lateral and central incisors on the right side was associated with ill-positioned germ of tooth 43 and intensified reaction to inadequate orthodontic forces.

\section{CONCLUSIONS}

Impacted mandibular canines are rare occurrences, of which management poses therapeutic difficulties. Aesthet- 
ics and occlusion determine the proper choice of treatment, so that the canine is brought back to the arch by using surgical and orthodontic extrusion. In order to minimize the risk of complications, early diagnosis is necessary as well as close interdisciplinary cooperation of an orthodontist and surgeon.

\section{CONFLICT OF INTEREST}

The authors declare no potential conflicts of interest with respect to the research, authorship, and/or publication of this article.

\section{References}

1. Andreasen JO, Petersen JK, Laskin DM. Textbook and Color Atlas of Tooth Impactions. Copenhagen: Munksgaard; 1997: 199-208.

2. D’Amico RM, Bjerklin K, Kurol J, Falahat B. Long-term results of orthodontic treatment of impacted maxillary canines. Angle Orthod 2003; 73: 231-238.

3. Agarwal S, Yadav S, Shah NV, Valiathan A, Uribe F, Nanda R. Correction of bilateral impacted mandibular canines with a lip bumper for anchorage reinforcement. Am J Orthod Dentofacial Orthop 2013; 143: 393-403.

4. Aydin U, Yilmaz HH, Yildirim D. Incidence of canine impaction and transmigration in a patient population. Dentomaxillofac Radiol 2004; 33: 164-169.

5. Grover PS, Lorton L. The incidence of unerupted permanent teeth and related clinical cases. Oral Surg Oral Med Oral Pathol 1985; 59: 420-425.

6. Chu FC, Li TK, Lui VK, et al. Prevalence of impacted teeth and associated pathologies-a radiographic study of the Hong Kong Chinese population. Hong Kong Med J 2003; 9: 158-163.

7. Ericson S, Kurol J. Radiografic examination of ectopicaly eruption maxillary canine. Am J Orthod Dentogac Orthop 1987; 91: 483-492.

8. Nodine AM. Aberrant teeth, their history, causes and treatment. Dent Items Interest 1943; 65: 440-451.

9. Selim Yavuz M, Hamdi Aras M, Cemil Buyukkurt M. Impacted mandibular canines. J Contemp Dent Pract 2007; 7: 78-85.

10. Mlosek K. Skuteczność diagnostyczna pantomografii. Czas Stomat 1978; 31: 924-941

11. Magnusson C, Kjellberg H. Impaction and retention of second molars: diagnosis, treatment and outcome. Angle Orthod 2009; 79: 422-427.

12. Camilleri S, Scerri E. Transmigration of mandibular cannes - a review of literature and a report of five cases. Angle Orthod 2003; 73: 753-762.

13. Aras MH, Halicioğlu K, Yavuz MS, Çağlaroğlu M. Evaluation of surgical-orthodontic treatments on impacted mandibular canines. Med Oral Patol Oral Cir Bucal 2011; 16: 925-928.

14. Paradowska-Stolarz A, Rzepecka-Skupień M, Chojnowski Sz, Sławecki K, Kawala B. Postępowanie ortodontyczne i ortodontyczno-chirurgiczne z kłami zatrzymanymi - przegląd piśmiennictwa. Dental Forum 2014; 42: 43-50.

15. Biedziak B, Szponar-Żurowska A, Kurzawski M. Usuwanie stałych górnych kłów w leczeniu ortodontycznym. Dent Med Probl 2006; 43: $257-262$.

16. Łoboda M. Przypadek czterech zatrzymanych kłów stałych u 17-letniej pacjentki. Por Stomatol 2010; 10: 132-135.

17. Szarmach I, Waszkiel D, Marczuk-Kolada G. Wpływ wieku badanych na przebieg i czas sprowadzania zatrzymanych kłów w szczęce do łuku zębowego. Czas Stomat 2006; 59: 118-125.

18. Orton HS, Garvey MT, Pearson MH. Extrusion of the ectopic maxillary canine using a lower removable appliance. Am J Orthod Dentofacial Orthop 1995; 107: 349-359.
19. Iramaneerat $S$, Cunningham SJ, Horrocks EN. The effect of two alternative methods of canine exposure upon subsequent duration of orthodontic treatment. Int J Paediatr Dent 1998; 8: 123-129.

20. Vermette ME, Kokich VG, Kennedy DB. Uncovering labially impacted teeth: apically positioned flap and closed-eruption techniques. Angle Orthod 1995; 65: 23-32.

21. Antoszewska J, Papadopoulos MA, Park HS, Ludwig B. Five year experience with orthodontic miniscrew implants: a retrospective investigation of factors influencing success rates. Am J Orthod Dentofac Orthop 2009; 136: 158.e1-158.e10.

22. Adamczyk H. Przegląd metod postępowania z zębami zatrzymanymi. Czas Stomat 1987; 40: 122-124.

23. Rayne JO. The unerupted maxillary canine. Dent Pract 1969; 19: 194-204.

24. Kawala B, Szeląg J. Postępowanie ortodontyczno-chirurgiczne w nietypowych przypadkach zębów zatrzymanych. Dent Med Probl 2003; 40: 355-362.

25. Tolstunov L. Implant zones of the jaws: implant location and related successrate. J Oral Implantol 2007; 33: 211-220.

26. Trivedi B, Jayam C, Bandlapalli A, Patel N. Surgical and orthodontic management of a horizontally impacted permanent mandibular canine: timing is vital. BMJ Case Rep 2014; 2014; doi: 10.1136/ bcr-2014-205052.

27. Doniec-Zawidzka I. Ortodontyczno-chirurgiczne sprowadzanie zębów zatrzymanych z zachowaniem prawidłowej długości koron klinicznych. Czas Stomat 1998; 51: 479-483. 